\title{
OBTENÇÃO DAS CURVAS DE EMBEBIÇÃO DE SEMENTES REVESTIDAS E NÃO REVESTIDAS DE Urochloa brizantha E Urochloa ruziziensis
}

Luciana Oliveira Derré, Ceci Castilho Custódio, Edna Antônia Torquato de Agostini, Wellington Eduardo Xavier Guerra

Universidade do Oeste Paulista - UNOESTE, Presidente Prudente, SP.

Correspondência para Ceci Castilho Custódio: ceci@unoeste.br

\section{RESUMO}

A indústria sementeira nacional está em franca expansão, atendendo demandas de exportação e importação. Devido ao aumento das exigências por qualidade, as indústrias desenvolveram tratamentos de revestimento, a fim de agregar valor às sementes. $O$ objetivo desta pesquisa foi avaliar sementes disponíveis comercialmente de Urochloa brizantha cv Xaraés e Urochloa ruziziensis cv Kennedy (Ruziziensis) revestidas e não revestidas quanto à sua capacidade de embebição. O experimento foi conduzido no Laboratório de Análises de Sementes da Universidade do Oeste Paulista (UNOESTE). Foram utilizadas sementes originárias de mesmo lote para ambos os cultivares. Para determinação da curva de embebição foram realizadas três repetições de 100 sementes por tratamento (presença e ausência de revestimento) e por período de embebição (0, $1,2,3,4,5,6,7,8,9,10,12,24,48,72,96,120$ e 144 horas). Os dados de embebição foram utilizados para calcular o grau de umidade da semente, em percentagem. $O$ experimento foi conduzido em delineamento inteiramente casualizado, em esquema fatorial ( $2 \times 18)$. Aplicou-se teste $F$, comparação de médias por teste Tukey $(P<0.05)$ e estudo de regressão polinomial. $A$ embebição foi mais rápida nas sementes sem revestimento e a protrusão da raiz primária iniciouse em torno de $72 \mathrm{~h}$ após o início do processo. Concluiu-se que sementes revestidas apresentam absorção de água mais lenta, o que pode ser vantajoso uma vez que a rápida absorção de água pode causar danos aos tecidos das mesmas.

Palavras-chave: germinação; grau de umidade; absorção de água.

\section{WATER UPTAKE TIME COURSES FOR COATED AND UNCOATED Urochloa brizantha AND Urochloa ruziziensis SEEDS}

\begin{abstract}
The national seed industry is growing meeting the demands of exportation and importation. Due to quality increasing demands, the industry developed coating treatments in order to add seeds value. The objective of this research was to evaluate the water uptake of Urochloa brizantha cv Xaraés and Urochloa ruziziensis cv Kennedy (Ruziziensis) commercially available seeds, coated and uncoated. The experiment was conducted at Seed Analysis Laboratory, University of Oeste Paulista (UNOESTE). Coated and uncoated seeds from the same batch were used. For water uptake time course determination, three replications of 100 seeds per treatment (coated and uncoated) and soaking period $(0,1,2,3,4,5,6,7,8,9,10,12,24,48,72,96,120$ e 144 hours) were performed. The imbibition data were used to calculate the seed moisture content in percentage. The experiment was conducted in a completely randomized design using a factorial arranged of the treatments $(2 \times 18)$. It was used the F-test, means comparison by Tukey test ( $P$ $<0.05$ ) and polynomial regression. Imbibition was faster in uncoated seed and radicle protrusion begins around $72 \mathrm{~h}$ after the beginning of the process. It was found that coated seeds delayed
\end{abstract}


water absorption, which can be advantageous since the rapid water absorption may cause seed tissue damage.

Keywords: germination; moisture content; water absorption. 


\section{INTRODUÇÃO}

A partir da década de 70 iniciouse expressiva implantação de pastagens no Brasil, tendo como destaque a propagação por sementes, em substituição às tradicionais mudas (BRITES, JUNIOR; TORRES, 2011). Nesse período ocorreu uma grande expansão de Brachiaria spp. em áreas de cerrado, proporcionando um aumento das áreas de pastagem no país, que passaram de 30 para 100 milhões de hectares (EUCLIDES et al., 2010). Estima-se que as áreas de pastagens representem 210 milhões de hectares, ocupando em torno de $76 \%$ da superfície utilizada pela agricultura e $20 \%$ da área total do país; sendo que o gênero Urochloa spp. (antigo Brachiaria) é utilizado em $60 \%$ dessas áreas (OLIVEIRA, 2010).

O aumento na demanda por sementes forrageiras impulsionou 0 desenvolvimento da indústria sementeira do Brasil, destacando-o como o maior exportador e consumidor de sementes de forrageiras tropicais. Em torno de $95 \%$ da produção dessas sementes são destinadas ao comércio interno e o restante é exportado, principalmente para países da América do Sul e Central (MARCHI et al., 2007). Destaca-se que a importância econômica das sementes de gramíneas forrageiras só é menor quando comparada às sementes de soja, movimentando valores acima de 300 milhões de reais anualmente (GERALDI JUNIOR, 2012).

Os cultivares do gênero Urochloa dominam mais de $80 \%$ do mercado, cuja finalidade é para a formação de pastagens (BRITES, JUNIOR; TORRES, 2011). Trata-se de um gênero que apresenta ampla adaptação de suas espécies às condições edafoclimáticas do cerrado, principalmente em regiões de solos ácidos e de baixa fertilidade (ALVIM; BOTREL; XAVIER, 2000).

A fim de agregar valor às sementes, o revestimento é uma ferramenta que confere proteção às sementes tanto no campo como durante o período de armazenamento, o qual pode se estender por um tempo maior que 12 meses (JULIATTI, 2010).

O revestimento das sementes de Urochloa é uma das técnicas mais eficazes no tratamento pré-semeadura, pelo fato de dar proteção às sementes contra agentes externos, possibilitar o fornecimento de nutrientes, oxigênio e reguladores de crescimento, oferecer proteção fitossanitária e herbicida e também por permitir uma semeadura de precisão em cultivos como o plantio direto (SANTOS et al., 2011; ).

A utilização dos revestimentos de sementes visa garantir a emergência das mesmas, ou seja, facilitar e aperfeiçoar sua semeadura. Não menos importante é a função do revestimento na viabilização de 
quaisquer tratamentos de sementes que sejam necessários para um bom estabelecimento inicial da cultura no campo (GADOTTI; PUCHALA, 2010).

O objetivo desta pesquisa foi avaliar sementes disponíveis comercialmente de Urochloa brizantha cv Xaraés e Urochloa ruziziensis cv Kennedy (Ruziziensis) revestidas e não revestidas quanto à sua capacidade de embebição.

\section{MATERIAL E MÉTODOS}

O experimento foi conduzido no Laboratório de Análise de Sementes da Universidade do Oeste Paulista (UNOESTE), em Presidente Prudente (SP), em 2013. Foram utilizadas sementes comerciais de Urochloa brizantha cv Xaraés e Urochloa ruziziensis cV Kennedy (Ruziziensis) não escarificadas, com e sem revestimento, o qual era composto por grafite, polímero, fungicidas e inseticidas de acordo com informações da empresa produtora de sementes. As sementes tratadas e não tratadas eram provenientes dos mesmos lotes, os quais foram obtidos junto à empresa Sementes Oeste Paulista (SOESP).

Para determinação da curva de embebição, foram separadas três repetições de 100 sementes por tratamento e por período de embebição $(0,1,2,3,4,5,6,7,8$, $9,10,12,24,48,72,96,120$ e 144 horas). As sementes foram colocadas em caixas plásticas para germinação, sobre papel umedecido com água destilada, a 25 으, como descrito para o teste de germinação (BRASIL, 2009). Decorrido cada período, as sementes úmidas foram colocadas em latas previamente mantidas em estufa a 25 으, pesadas, e novamente levadas para estufa a 105 C por 24 horas, para obtenção da massa seca. Os dados obtidos foram utilizados para calcular o grau de umidade, em percentagem (BRASIL, 2009).

Os experimentos foram conduzidos em delineamento inteiramente casualizado com três repetições por tratamento. Para a determinação da curva de embebição foram consideradas para cada espécie, as sementes com e sem revestimento e os períodos de avaliação (fatorial $2 \times 18$ ). Aplicou-se teste $F$ e os tratamentos qualitativos foram avaliados por comparação de médias (teste de Tukey com $5 \%$ de probabilidade), enquanto que os tratamentos quantitativos foram estudados por regressão polinomial. Foi utilizado o aplicativo SISVAR (FERREIRA, 2011).

\section{RESULTADOS E DISCUSSÃO}

A embebição das sementes avaliadas pode ser observada nas Figuras $1 \mathrm{e}$ 2, sendo caracterizada por uma curva trifásica. Foi possível verificar que as sementes sem revestimento apresentaram maior porcentagem de umidade quando 
comparadas com as sementes revestidas para ambas as cultivares analisadas, indicando que o tratamento com polímero reduziu a velocidade de embebição. Custódio et al. (2011) também observaram a redução na embebição de sementes peliculizadas, quando comparadas às sementes escarificas e intactas.

O comportamento da absorção de água, para o cultivar Xaraés, é apresentado na Figura 1, onde as sementes revestidas apresentaram diferença significativa de umidade, variando de $6 \%$ a $60 \%$, com umidade inferior às sementes sem revestimento, durante o decorrer da embebição. $\mathrm{O}$ incremento de umidade verificado no tempo de 72 horas ocorreu em resposta à protrusão radicular iniciada nas sementes sem revestimento.

Xaraés sem revestimento (S/R) e revestidas (R).

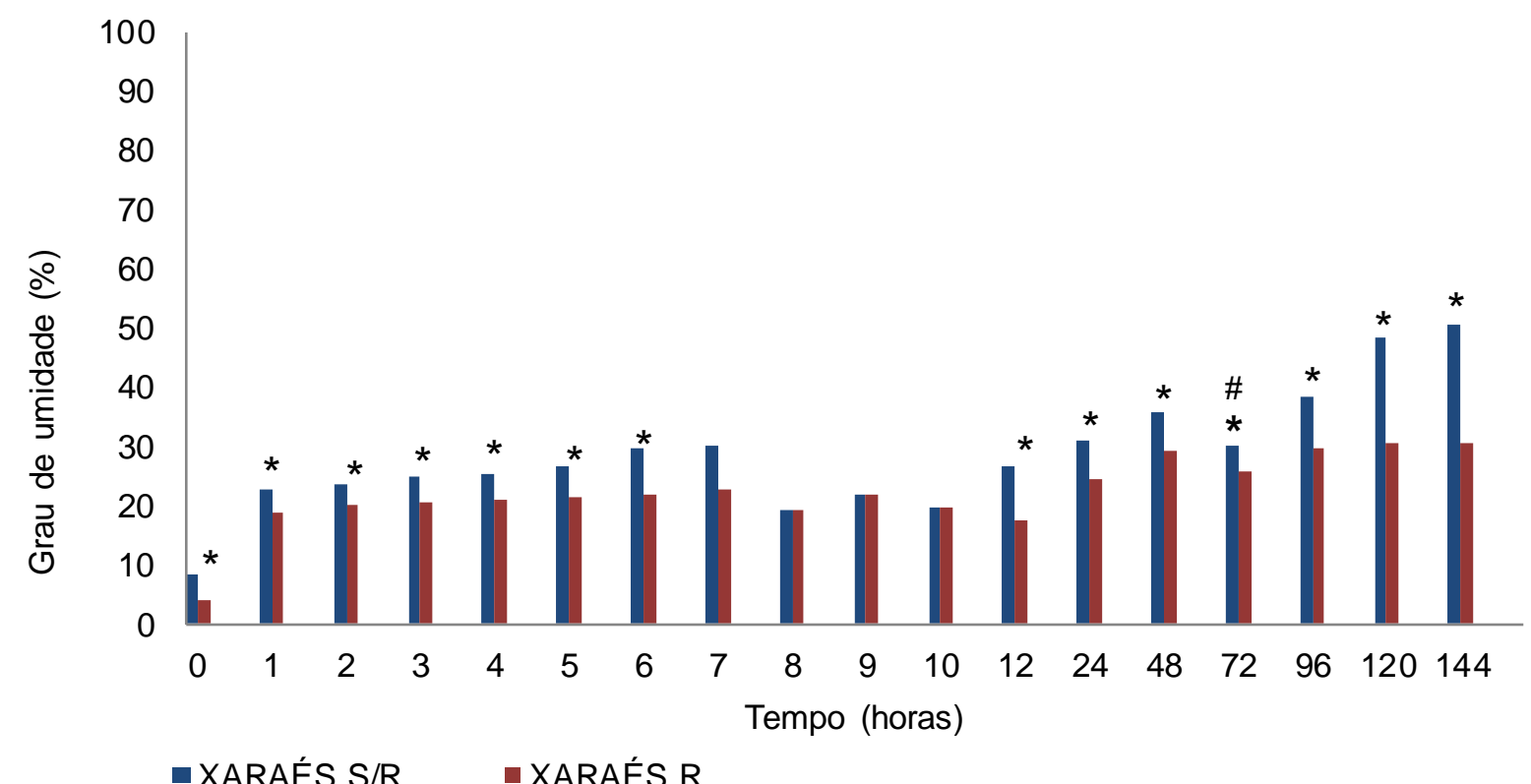

Figura 1. Grau de umidade (\%) durante a embebição de sementes de Urochloa brizantha cV *Diferença significativa a $5 \%$ de probabilidade pelo Teste $\mathrm{F}$.

\# Início visível da germinação com emissão de radícula, S/R 1,33\%.

Seguindo o modelo trifásico (BEWLEY; BLACK, 1994), considerou-se que a Fase I de embebição ocorreu na primeira hora, possibilitando crescente aumento na taxa inicial de embebição. Essa fase caracteriza-se por um processo físico de rápida transferência de água do substrato para a semente, devido à acentuada diferença entre os potenciais hídricos (MARCOS FILHO, 2005). Após um tempo um 
verificou-se uma estabilização no ganho de massa, demonstrada pela lenta absorção de água, comumente encontrada na Fase II. Nesta fase, ocorre uma intensa atividade respiratória e acentuados processos metabólicos, importantes para o desenvolvimento e crescimento embrionário, estimulando a germinação, a qual é representada pela protrusão radicular, dando início à Fase III. Desta maneira, iniciada a Fase III, ocorre um acelerado ganho de umidade, devido à necessidade de água pelas novas células da plântula em processo de formação, ocorrendo assim a protrusão radicular a partir das 72 horas de embebição, para as sementes sem revestimento.

A evolução da absorção de água para o cultivar Ruziziensis (Figura 2) apresentou significância a partir da Fase II da curva de embebição, porém foi na Fase III onde ocorreu maior diferença de umidade entre os tratamentos, devido ao início da protrusão radicular a partir de 72 horas de embebição.

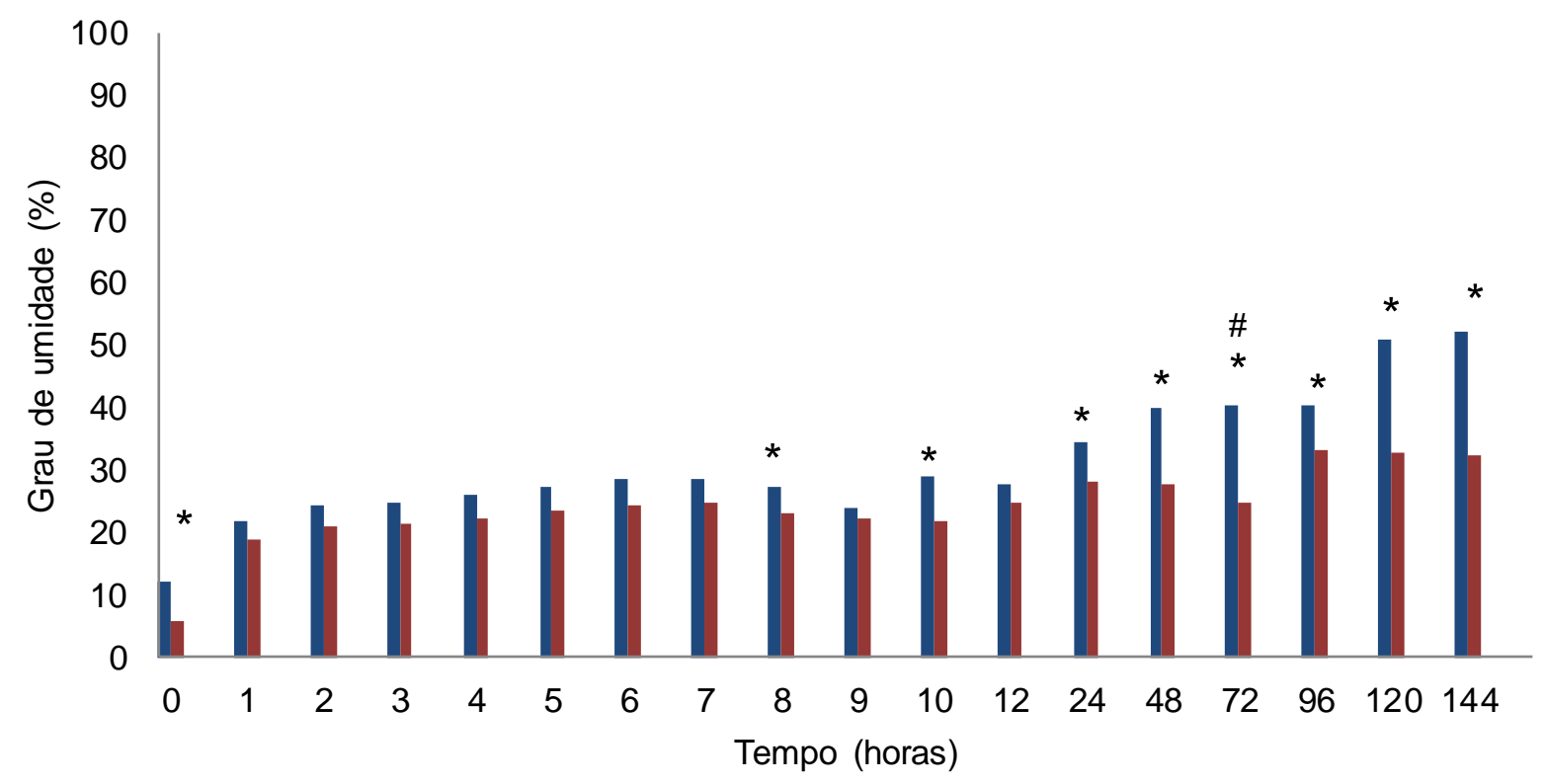

- RUZIZIENSIS S/R - RUZIZIENSIS R

Figura 2. Grau de umidade (\%) durante a embebição de sementes de Urochloa ruziziensis cv Kennedy (Ruziziensis) sem revestimento (S/R) e revestidas (R).

*Diferença significativa a $5 \%$ de probabilidade pelo Teste $\mathrm{F}$.

\# Inicio visível da germinação com emissão de radícula, S/R 3\% e R 2,66\%.

O aumento visível de umidade ocorrido em ambas as cultivares, a partir da Fase III da curva de embebição é amparada pela colocação de Egli e Teknony (1997), os quais sugerem que durante a embebição os tecidos de reserva que encontravam-se 
secos, passam a ser hidrolisados e a semente inicia o acúmulo de solutos. Dessa forma, a pressão hidrostática de turgor pode aumentar através do acúmulo de solutos osmóticos, permitindo que a radícula cresça e ultrapasse os tecidos que a envolvem (BRADFORD, 1995).

$$
\text { Powell e Mathews }
$$

afirmaram que a velocidade com que a água penetra nos tecidos das sementes tem fundamental importância no sucesso da germinação, pois quando a semente é colocada em contato com a água pura, a embebição ocorre de maneira muito rápida, podendo ocasionar danos ou injúrias em alguns tecidos. Costa et al. (2001) destacam que as sementes revestidas demoram mais tempo para absorver a umidade do solo, podendo retardar sua germinação em até 48 horas em relação às sementes sem revestimento.

A primeira estrutura celular a sofrer ação da embebição de água são as membrana celulares, compostas de uma camada de fosfolipídios que possuem extremidades hidrofílicas voltadas para o meio externo ao conteúdo celular e cadeias hidrofóbicas que estão associadas à parede interna das membranas (TAIZ; ZEIGER, 2004). Assim, a estrutura é dependente da presença de água para a manutenção da sua orientação hidrofóbica/hidrofílica, dependência esta que é afetada pela

ausência de água aquando há desidratação da semente. A membrana então muda normalmente do estado mais fluído, ou estado cristalino líquido, para o estado menos fluído, também denominado estado de gel. Sob esta condição, ocorre um efeito de empacotamento e aproximação das moléculas, restringindo seu movimento. A transição entre os estados de gel e cristalino líquido também depende da temperatura. Se as membranas desidratadas forem aquecidas, elas poderão entrar em estado de fusão ("melting"), passando para o estado cristalino líquido. Se a água for então introduzida, acontecerá certo nível de extravasamento de eletrólitos celulares, caracterizando o dano celular (CASTRO; HILHORST, 2004; GUIMARÃES; DIAS; LOUREIRO, 2008).

\section{CONCLUSÃO}

Através da obtenção da curva de embebição foi possível observar que as sementes revestidas, independentemente da cultivar, apresentam menor absorção de água, o que pode restringir a germinação ou pode ser vantajoso, uma vez que a rápida absorção de água pode causar danos aos tecidos das mesmas e consequentemente um baixo índice de germinação.

\section{REFERÊNCIAS}


ALVIM, M.J.; BOTREL, M.A.; XAVIER, D.F. As espécies de Urochloa utilizadas no país. Juiz de Fora, MG: Ministério da Agricultura e Abastecimento, 2000. (Comunicado Técnico, n.22)

BEWLEY, J.D.; BLACK, M. Seeds: physiology of development and germination. 2. ed. New York: Plenum Press, 1994.

BRADFORD, K.J. Water relations in seed germination. In: KIJEL, J.; GALILI, G. (eds.). Seed development and germination. New York: Marcel Dekker, 1995. p.351-395.

BRASIL. Ministério da Agricultura, Pecuária e Abastecimento. Secretaria de Defesa Agropecuária. Regras para análise de sementes. Brasília: Ministério da Agricultura, Pecuária e Abastecimento, 2009.

BRITES, F.H.R.; JUNIOR, C.A.; TORRES, F.E. Germinação de semente comum, escarificada e revestida de diferentes espécies forrageiras tropicais. Bioscience Journal, v.27, n.4, p.629-634, 2011.

CASTRO, R.D.; HILHORST, RH. Embebição e reativação do metabolismo. In: FERREIRA, A.G.; BORGHETTI, F. Germinação: do básico ao aplicado. Porto Alegre: Artmed, 2004. p.149-162.

COSTA, C.E.L.; SILVA, R.F.; LIMA, J.O.G.; ARAÚJO, R.F. Sementes de cenoura Daucus carota L., revestidas e peliculadas: germinação e vigor durante o armazenamento. Revista Brasileira de Armazenamento, v.26, p. 30-45, 2001.

CUSTÓDIO, C.C.; AMBIEL, A.C.; RODRIGUES, D.Z.; AGOSTINI, E.A.; FACTUR, V.D.; PAVANELLI, L.E. Peliculização de sementes intactas e escarificadas de Brachiaria brizantha (Hochst. Ex A. Rich) Staf. Pesquisa Agropecuária Tropical, v.41, p.314-321, 2011. DOI: 10.5216
EGLI, D.B.; TEKRONY, D.M. Species differences in seed water status during seed maturation and germination. Seed Science Research, v.7, p.3-11. 1997. http://dx.doi.org/10.1017/S09602585000033 05

EUCLIDES, V. P. B.; VALLE, C.B.; MACEDO, M.C.M.; ALMEIDA, R.G.;MONTAGNER, D.B.; BARBOSA, R.A. Brazilian scientific progress in pasture research during the first decade of XXI century. Revista Brasileira de Zootecnia, v.39, (supl.), p.151-168, 2010. http://dx.doi.org/10.1590/S151635982010001300018

FERREIRA, D.F. SISVAR: a computer statical analysis system. Ciência e Agrotecnologia, v.35, p.1039-1042, 2011. http://dx.doi.org/10.1590/S141370542011000600001.

GADOTTI, C.; PUCHALA, B. Revestimento de sementes. Informativo ABRATES, v.20, p.7071, 2010.

GERALDI JUNIOR, G. Pastagem: a importância das sementes na sua perfeita implantação. Pastagem e Forrageiras, 2012. Disponível em: http://www.zoonews.com.br/noticiax.php?id noticia $=1894 \& a=v i e w$. Acesso em: 11 de ago. 2013.

GUIMARÃES, M.A.; DIAS, D.C.F.S.; LOUREIRO, M.E. Hidratação de sementes. Revista Trópica - Ciências Agrarias e Biológicas, v.2, p.31, 2008.

JULIATTI, F.C. Avanços no tratamento químico de sementes. Informativo ABRATES, v.20, p.54-55, 2010.

MARCHI, C.E.; FERNANDES, C.D.; BORGES, C.T.; SANTOS, J.M.; JERBA, V.F.; TRENTIN, R.A.; GUIMARÃES, L.R.A. Nematofauna fitopatogênica de sementes comerciais de forrageiras tropicais. Pesquisa Agropecuária Brasileira, v.42, p.655-660, 2007. http://dx.doi.org/10.1590/S0100204X2007000500007 
MARCOS FILHO, J. Fisiologia de sementes de plantas cultivadas. Piracicaba: Fealq, 2005.

OLIVEIRA, L.E.V. Estabelecimento de pastagens. Sobral: Programa de PósGraduação em Zootecnia UVA/Embrapa, 2010. Disponível em: http://www.ebah.com.br/content/ABAAABV yoAB/formacao-pastagens Acesso em: 15 de ago. 2013.

POWELL, A.A.; MATHEWS, S. The damaging effect of water on dry pea embryos during imbibition. Journal of Experimental Botany, v.29, p.1215-1229, 1978. http://dx.doi.org/10.1093/jxb/29.5.1215

SANTOS, L.D.C.; BENETT, C.G.S.; SILVA, K.S.; SILVA, L.V. Germinação de diferentes tipos de sementes de Brachiaira brizantha cv. BRS Piatã. Bioscience Journal, v.27, p.420-426, 2011.

TAIZ, L.; ZEIGER, E. Fisiologia vegetal. 3. ed. Porto Alegre: Artmed, 2004.

Recebido para publicação em 08/11/2013

Revisado em 17/02/2014

Aceito em 07/04/2014 